\title{
UBUNTU COMO MODO DE VIDA: CONTRIBUIÇÃO DA FILOSOFIA AFRICANA PARA PENSAR A DEMOCRACIA ${ }^{1}$
}

\author{
Antonio Oliveira Dju ${ }^{2}$ \\ Darcisio Natal Muraro ${ }^{3}$
}

Resumo: O objetivo deste estudo é analisar a noçẫo do Ubuntu como contribuição para pensar a democracia, especialmente a crise que esta enfrenta, no Brasil, da atual realidade histórica de intolerância, discriminação racial, exclusão social e desumanizaçáo. Para isso, levanta-se a seguinte questấo: pode a África contribuir para o pensamento da democracia, pela sua filosofia de vida expressa em Ubuntu? A primeira parte do texto analisa o conceito de Ubuntu, destacando seu caráter filosófico. A segunda parte desenvolve duas características estruturais do Ubuntu: a comunidade e a tolerância. A metodologia de pesquisa se caracteriza como um trabalho bibliográfico, cujo aporte é a análise filosófica da expressão Ubuntu, fundamentada no modo de vida africano, a partir das obras de Ramose: African Philosophy Through Ubuntu (2005); de Gyekye: Person and Community in African Thought (2003). Entende-se que compreender Ubuntu como um modo de vida africano, baseado na interdependência, interconstituição, interconexão e inter-humanização é cooperar para pensar a democracia como modo de vida ético, social e político, o qual reconhece e considera o(s) outro(s) como sujeito(s) de diferenças que possibilitam a humanização.

Palavras-chave: Ubuntu. Comunidade. Tolerância. Democracia. Filosofia africana.

\footnotetext{
${ }^{1}$ Este artigo foi desenvolvido a partir da Dissertação de Mestrado, cujo tema é "Alteridade e Educação: contribuição de Paulo Freire e da Filosofia Ubuntu para um Educação Humanizadora”, a qual contou com apoio financeiro da Coordenação de Aperfeiçoamento de Pessoal de Nível Superior (CAPES) ,por meio de bolsa de estudos de Mestrado.

2 Doutorando em Educação pelo Programa de Pós-Graduação em Educação - Universidade Estadual de Londrina (UEL), Londrina, PR - Brasil. (D) https://orcid.org/0000-0001-8954-2145. E-mail: antoniodju@yahoo.it.

3 Professor adjunto do Departamento de Educação da Universidade Estadual de Londrina (UEL), Londrina, PR - Brasil. (iD https://orcid.org/0000-0002-5413-8385. E-mail: murarodnm@gmail.com.

https://doi.org/10.1590/0101-3173.2022.v45esp.13.p239
}

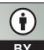

This is an open-access article distributed under the terms of the Creative Commons Attribution License. 


\section{INTRODUÇÃo}

Assistimos à explosão de protestos antirracistas e contra discriminação sociopolítica à base da cor da pele, feitos por movimentos negros e seus simpatizantes, em diversos lugares no mundo, com forte ressonância nas redes sociais. É sinal claro de que o problema acerca dessas diferenças entre pessoas necessita ser enfrentado com corajosa reflexão crítica. Movimento como Black lives matter (vidas negras importam) faz diferença, nessa luta. A gravidade do problema que é trazido a público, por meio de protestos e pela exploração midiática, geralmente por sensacionalismo, quando um negro é assassinado especialmente por quem deveria defendê-lo, é apenas a ponta do iceberg. É assustador e causa indignação a população negra morando nas periferias das grandes cidades, nas favelas, cortiços e ruas, recebendo os piores salários e trabalhos, impossibilitada de usar serviços públicos, como saúde e educação de qualidade, perseguida pela polícia e sendo insultada até pela linguagem, como no uso de termos como "denegrir". Esses protestos reacendem a problemática discussão sobre o tratamento dos negros e de suas culturas, na sociedade, isto é, sobre o racismo, preconceito e discriminação racial. Por que ainda há a exclusão às culturas negras da vida social, em sociedades que se autoproclamam democráticas?

Os pretos, referindo-nos à cor da pele, ao longo da história, foram vistos como seres de segunda categoria, isto é, inferiores em relação aos seres hegemônicos brancos. Eles foram arrancados da África, despidos de suas culturas, histórias e identidades, e vendidos como mercadorias pelo mundo, na condição de escravos. Muitos deles foram trazidos para a América. E, nessa condição opressora de escravidão, longe de suas comunidades, os escravos foram proibidos e impossibilitados de expressar suas culturas africanas. E não tinham direito a nada. Eram submetidos à supremacia branca, que os considera inferiores. Essa submissão não foi pacífica, isto é, houve resistência da parte dos escravos, os quais foram violentamente reprimidos. Em outras palavras, a submissão se deu pela violência, que continua afligindo os descendentes: violência policial, violência econômica e violência política.

O tratamento das culturas negras, no Brasil, reflete a exclusão por essas violências. Basta vermos a pobreza, a violência policial, a política fascista brasileira e os refugiados, em termos internacionais. Para pensar a democracia, esse problema necessita ser tratado com seriedade e com ampla participaçáo. A democracia vem sendo pensada, construída e refletida constantemente como um sistema político social que rege a vida dos seres humanos na sociedade como 
um todo. Sua concepção não é acabada. Ela nutre mudança constante, cuja experiência os seres humanos vêm debatendo e construindo percepçóes, desde a era grega. Tomamos a noção do termo, neste texto, a partir de Freire (2002), como sendo modo de vida dialógico e compartilhado dos seres humanos que agem no mundo, de forma integrada e temporalizada, para transformá-lo. Em outras palavras, refere-se à correspondência entre as disposiçóes mentais com o agir dos seres humanos. A princípio, essa forma de vida se estrutura na mudança e estabilidade, que são dois elementos característicos da sociedade, isto é, mantém as relaçóes conflitosas e equilibradas. Esse jeito de viver a vida estende-se à dimensão sociopolítica.

Ubuntu se tornou foco de estudo de várias ciências, incluindo a educação, desde a década de 1990, justamente por ele ter sido acionado pelos sul-africanos no resgate da humanização diante da política de apartheid (aplicada na África do Sul, de 1948 a 1994). E há quem acredite que o desenvolvimento políticosocial na África do Sul se deve a esse acionamento do Ubuntu. Tomamos o conceito de humano/humanização, neste artigo, no sentido freiriano, como integração com o mundo, a partir da ética da libertação e da solidariedade, em processo sócio-histórico-cultural de "ser mais". É um termo fundado na ética. Em outras palavras, só é humano/humanização quem, cujo rigor ético almeja a defesa da dignidade humana. É isso que Freire (2011) entende por ética universal do ser humano, da qual se deve pensar a vida, as relaçôes entre os humanos e com o mundo. E a desumanização, em Freire (1987), como impossibilidade ou ausência da liberdade, da condição de "ser mais", vista na situação de opressão, colonização, neocolonização.

A provocação para a discussão deste texto partiu de uma realidade característica atual. Refere-se à intolerância, discriminação racial e exclusão praticada no atual cenário sociopolítico. Com a polarização política, assistimos a pessoas ou movimentos reclamarem o direito de falar, apoiar e defender seus políticos, a tortura e a violência contra os outros. Essas pessoas acreditam estar em seus direitos de "assassinar" a imagem dos outros, nas redes sociais, e de distorcer os dados científicos, criando fake news e mitos falaciosos. E quando os outros acionam o mesmo direito de falar e de manifestar suas ideias e posiçóes políticas, são ameaçados e agredidos verbal e fisicamente. O que essa situação - a da intolerância e da discriminação - nos faz questionar, em termos de nossa discussão sobre a democracia, é: para vivermos, precisamos excluir, eliminar os diferentes? Por que insistimos no dualismo entre os direitos do indivíduo e os do coletivo (comunidade), como se não estivessem interconectados? 
Por um lado, vive-se numa era quando se fala muito de identidade e diferença, isto é, modo de ser das pessoas nas suas variedades culturais, referindo-se à filosofia de alteridade, na qual o reconhecimento do outro quanto à sua identidade, valores e cultura conta muito. Isso quer dizer que não se deve mais pensar em pessoa, experiência, verdade, conhecimento, valor, de forma unilateral. Pelo contrário, busca-se pensar isso de forma inclusiva e democrática. Por outro, vive-se também, ao mesmo tempo, uma desconstrução da democracia, pela ideologização polarizada, desinformaçáo, preconceito, racismo, miséria, autoritarismo, alienação, manipulação dos outros para o proveito próprio.

Parece uma contradição entre o que é dito e o que é feito. Por isso, questionamos: pode-se falar em democracia, num país como o Brasil, onde os direitos básicos da maioria são roubados? Isso não seria uma contradição? Pode a África contribuir para o pensamento da democracia, no Brasil, pela sua filosofia de vida expressa em Ubuntu?

O presente texto possui por objetivo discutir a noção do Ubuntu como contribuição para pensar a democracia, diante de uma realidade histórica de desumanização. Definiu-se como metodologia uma pesquisa teórica enquanto parte de nossa pesquisa de Mestrado ${ }^{4}$, cujo foco investigativo está na questão do Ubuntu e a educação humanizadora. Como referencial teórico-base estão as obras de Ramose, African Philosophy Through Ubuntu (2005), e de Gyekye, Person and community in African thought (2003). A justificativa da escolha desses autores e suas obras se dá pelo fato de Ramose ter feito a análise de uma filosofia africana, a partir da expressão Ubuntu; e de Gyekye ter-se considerado um pensador moderado, na discussão sobre a relação entre o indivíduo e a comunidade. É com base na interdependência e interconexão como modo de vida africano que propomos pensar a democracia.

\section{Filosofia AFricana EXPRESSA EM $U$ BUNTU COMO MODO DE VIDA}

Ubuntué um conceito que expressa a filosofia de vida africana, originário dos povos Bantu. ${ }^{5}$ Despertou recentemente a atenção dos pesquisadores de várias áreas de conhecimento, por ele ser a causa de desenvolvimento político,

\footnotetext{
${ }_{4}^{4}$ Trata-se da pesquisa feita na Dissertação de Mestrado de Antonio Oliveira Dju, defendida no Progrma de Pós-Graduação em Eduação da Universidade Estadual de Londrina (UEL), em ferereiro de 2021.

5 Povos Bantu são os falantes das línguas bantu, compostos por vários grupos étnicos da África subsaariana, principalmente na parte sul do continente.
} 
na África do Sul. É comum entre os povos africanos usar certas expressóes que representam seus valores. Tempels (1959, p. 21) mostra isso, ao aludir aos Bantu: "Certas palavras são constantemente usadas pelos africanos. São aquelas que expressam seus valores supremos; e elas se repetem como variaçóes sobre um mantra presente em sua língua, seu pensamento, e em todos os seus atos e afazeres.”

Para os povos Bantu, segundo Tempels, esse valor supremo é a vida, a força, ou força vital, que é a própria pessoa humana. Uma dessas expressóes é Ubuntu, objeto deste texto, que está presente em muitas línguas dessas culturas africanas. Por ser uma filosofia de vida, Ubuntu pertence à tradição oral dos povos Bantu. Salienta Nabudere (2005, p. 1):

A filosofia bantu, nas suas várias formas, é a base da filosofia de vida africana e de sistemas de crenças, nas quais são refletidas as experiências diárias das pessoas. Em suas lutas para sobreviver e existir como sociedade humana neste planeta, os africanos tiveram uma longa experiência desde a era Homo Sapiens e primeiro lar no continente. A filosofia é usada diariamente para resolver disputas e conflitos em vários níveis no continente e, por isso, central à ideia de reconciliação.

Historicamente, o termo foi acionado algumas vezes, no século passado, na África do Sul, como proposta para resolver problemas sociopolíticos e éticos. Interessa-nos, para nossa discussão sobre a democracia vista do Ubuntu, a análise etimológica dessa expressão.

De acordo com Ramose (2005), linguisticamente, o termo Ubuntu deve ser tomado como uma palavra hifenizada: Ubu-Ntu. Ubu (prefixo) diz respeito à existência, na sua forma geral, como processo contínuo do ser que se torna constantemente, enquanto $n t u$ (raiz), à existência, na sua forma concreta. Com isso, o autor entende que Ubu, dentro desse processo de tornar-se, implica constante movimento, vir a ser, o qual deve ser visto como um verbo. Por sua vez, $n t u$ deve ser interpretado temporariamente como o ter-se tornado. Assim, Ntu é um nome substantivo. Ramose (2005, p. 36) assinala que "Ubu, abarcado como ser-sendo, está sempre orientado no sentido do abarcamento, isto é, uma manifestação concreta incessante e contínua por meio de formas e modos de ser. Assim, ubu- está sempre orientado na direção do -ntu.”

O autor ainda compara outro prefixo Bantu, umu (de umuntu), com ubu. Segundo ele, a palavra umu partilha a mesma característica ontológica da palavra ubu. Apesar dessa partilha, ainda para o autor, o alcance de $u b u$ é de 
maior generalidade. O sentido do Umuntu refere-se à emergência do homoloquens (o ser falante), a qual é a outra qualidade do ser humano. Em outras palavras, significa o ser-sendo humano, que faz a política, a religião e cria a lei. Assim, Ramose (2005, p. 36) entende que o "[...] umuntu é a manifestação concreta e específica de umu-: é um movimento que se afasta do geral para o específico materializado."

Sendo uma palavra não dicotomizada, Ubu-ntu é um "substantivo verbal". Cremos que talvez possamos comparar esse substantivo verbal com o processo da dinâmica entre reflexão-ação. Toda reflexão deve necessariamente levar à ação (substantivo) e esta, por sua vez, é reflexiva (verbal). Ramose (2005, p. 36) associa esse substantivo verbal (essas duas faces da mesma moeda) à ontologia e à epistemologia, que são duas categorias importantes no pensamento africano:

[...] ubu-ntu é a fundamental categoria ontológica e epistemológica no pensamento africano do povo de língua bantu. É a indivisível unicidade e inteireza da epistemologia e ontologia. Ubu, compreendido dinamicamente como ser/existência, pode ser dito ser distintamente ontológico. Enquanto $n t u$, que é o ponto no qual a existência assume uma forma concreta ou um modo de ser no processo contínuo de desdobramento, pode ser dito ser distintamente epistemológico.

Além de ser um nome verbal, Ubu-ntu é um gerúndio que faz a existência se tornar um processo dinâmico, isto é, ser-sendo. Essa ideia nos parece interessante, porque se aproxima da noçáo antropológica do existencialismo. Pela existência e coexistência, o ser humano adquire valores, qualidades que lhe são próprios, na sua relação com o mundo e com o Outro. Ao mesmo tempo que é gerúndio, conforme o autor, também é gerundivo ${ }^{6}$, pois em ação se cria uma forma verbal impessoal, já que pode se cristalizar, em nível epistemológico, numa forma particular de organização social, religiáo ou lei.

Ramose (2005) ainda nos esclarece que Ubuntu segue a lógica do sufixo ness (dade) e não do sufixo ism (ismo). O sufixo ness, em inglês, é formador de nomes referentes à qualidade ou à condição. Por exemplo: goodness (bondade),

${ }^{6}$ Gerundivo é a modalidade de gerúndio, na língua latina, com função de particípio passivo futuro de um verbo; exprime uma ação que está para se realizar ou que será realizada. Em português, há exemplos de derivaçấo disso - venerando, memorando, adendo - e do pl. neutro - como agenda, corrigenda, fazenda; há vários neologismos estruturados por esse modelo, como formando, diplomando, doutorando etc. 
badness (maldade), selfishness (egoísmo), maness (homem) denotam a qualidade ou a condição de ser bom, mau, egoísta, homem. E o sufixo ism é formador de nomes referentes à crença social, política e religiosa, ao estudo, à forma de comportamento. Os exemplos dessa ideia são os seguintes: sexism (sexismo), feminism (feminismo), homosexualism (homossexualismo), Catholicism (catolicismo), Fordism (fordismo). Ubu-ntu é essa lógica de condição ou qualidade de um ser humano ser-sendo humano, diferentemente da lógica dogmática fragmentista, a qual concebe ser humano como imutável.

De acordo com Ramose (2005), Ubu-ntu são duas realidades mutuamente fundidas, que se tornam indivisível unicidade e inteireza. O ser não é apenas existência, do ponto de vista essencialista, mas é também existência, do ponto de vista fenomenológico. A visão ontológica e epistemológica toma o indivíduo nesses dois aspetos. A ideia de a pessoa se tornar humana, incluindo o processo de conhecimento na relação com os pares, na concepção Ubuntu, mostra as categorias fundamentais da ontologia e da epistemologia. Essa ideia está presente em quase todas as experiências culturais de outros povos do continente africano. Por isso, alguns pensadores, como Ramose (2005), acreditam que o Ubuntu pode ser considerado a raiz da filosofia africana. Tornar-se humano, ontologicamente falando, é acreditar que a moção (vir a ser) é o princípio do ser. Isto é, os seres existem numa interação complexa constante e de mudança contínua, através do movimento. Isso quer dizer que o indivíduo é inconcluso, busca ser mais nessa constante mudança.

Tratar de Ubu é remeter à existência de um ser humano, isto é, à sua ontologia. Esse tipo de discussão é muito genérico e ideológico (no sentido de ideal), visto que aborda o motivo de ser humano em geral. E $n t u$ é exatamente esse ser humano físico, denominado fulano, que existe e se manifesta fenomenologicamente em um tempo e espaço, fazendo e criando história e cultura. Isso, sim, é epistemologia, porque contempla esse fulano na sua vivência fenomenológica como sujeito epistêmico e de experiência. Se o ser é força vital, o conhecimento e a sabedoria também o são, porque fazem as forças dos seres agir na sua natureza interior (TEMPELS, 1959). Assim, podemos sustentar que ntu é exatamente a manifestação visível desse ser humano teorizado no Ubu. Essa forma de pensar sobre o ser humano ideal e concreto é comum a várias culturas da África. No entanto, esse pensar não faz essas culturas serem dualistas: pelo contrário, elas são unicistas.

Para entendermos melhor essa forma de pensamento africano, usamos a seguir uma representação da cosmologia africana: 
Figura 1 - Cosmologia africana

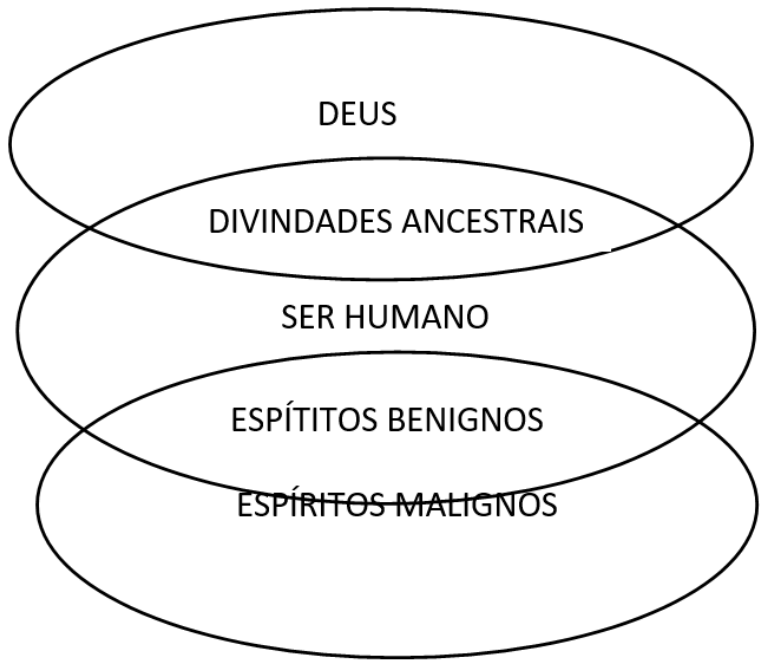

Fonte: KANU, 2015.

Nessa representação, percebemos que o ser humano é o centro do universo. Por isso, a filosofia africana pode ser compreendida a partir desse antropocentrismo cosmológico. Todas as outras divindades existem em função do ser humano africano. Entre ele e Deus, criador de todas a coisas, há divindades ancestrais, que fazem parte de sua existência. Portanto, para entender a ontologia do ser humano africano, é necessário abordá-la em relação com seu criador e seus ancestrais. Isto é, há uma estreita relação entre divindades (ontologia) e o africano concreto (espacial e temporal). Baseado nessa relação, sendo fenomenológico, o africano procura viver de forma equilibrada com essas divindades. Segundo Kanu (2017, p. 97), “[...] suas atividades diárias não são apenas projetadas para harmonizar sua relação com as divindades e ancestrais falecidos, mas também são motivados pelo medo que a má relação com esses seres espirituais possa trazer perigo à vida e à segurança de sua comunidade."

Harmonia com as divindades e ancestrais, na sua forma ontológica africana, exige que o africano viva em harmonia ou unidade com seus pares humanos, com os quais compóe a comunidade. A ontologia africana justifica a fenomenologia com os outros, os diferentes. porque a identidade 
e a diferença, em termos de alteridade, possuem a mesma ontologia, a mesma visão do mundo, a mesma cultura (pertencem à mesma cultura) e o mesmo destino, por isso, horizontalmente, são seres complementares, interdependentes, isto é, eles se completam um ao outro. Com base nesse pensamento de existir com, de pertencimento aos outros (comunidade), participando ativamente em sua vida, alguns filósofos africanos formularam aforismos que representam essa ontologia, em função de várias culturas. Só para citar alguns: o filósofo queniano Mbiti (1970, p. 141) afirma: “[...] eu sou, porque nós somos, e dado que somos, por isso eu sou"; Nkemnkia (apud KANU, 2017, p. 100), remetendo à importância do laço que o indivíduo tem com os outros, assevera:

O significado da vida de um indivíduo está no e através de seu relacionamento com o outro ou outros. $\mathrm{Na}$ verdade, náo faz sentido perguntar a si mesmo "quem sou eu" sem ter um conhecimento completo do Outro, de quem, em última análise, espera-se a resposta. Quando dizemos 'eu', na realidade significa 'Você', isto é, o Outro. Ao dizer "Nós" está-se essencialmente a dizer "homem". Se é assim que as coisas são, então cada 'eu', é sempre mediado pelo "Outro", que não é outro senão "a si mesmo". Nesta dialética cada um de nós contém exclusivamente o Outro.

Tudo isso é Ubuntu, que é uma das características para se tornar humano, isto é, a qualidade mais importante para a existência autêntica humana, diferente de coisa. Do sentido genérico de "qualidade humana", ubuu.ndu, yabantu', Ubuntu passou a ser pautado na ontologia africana. Isto é, passou-se ao aforismo Umuntu Ngumuntu Ngabantu/motho he motho ka batho, derivado das línguas Zulu e Xhosa, da África do Sul, de sorte que muitos autores reconhecem a dificuldade de traduzi-la para outras línguas. Por exemplo, Mabovula (2011) destaca que é uma expressão difícil de ser traduzida para línguas ocidentais, devido às limitaçóes destas.

No entanto, as traduçóes atribuídas e aceites, segundo Lötter e Marx (apud GADE, 2011, p. 313), são: "a pessoa se torna pessoa por causa dos outros"; "um ser humano só é um ser humano através de sua relação com outro ser humano". A partir de sua análise filosófica, Ramose (2005, p. 37) traz a seguinte interpretação: "Ubuntu é entendido como ser-sendo [be-ing]

\footnotetext{
7 ubuu.ndu é o termo para humanidade/humanização, em língua Chindali, falada em Tanzânia e Malawi. E yabatu é o termo em Zulu (África do Sul) para humanidade, no sentido coletivo. Ambas as línguas são Bantu. Esses dois termos referem-se à qualidade de ser humano.
} 
humanidade [...]" E isso consiste em significar que "ser-sendo humano é afirmar a humanidade do indivíduo pelo reconhecimento da humanidade dos outros e, assim, estabelecer as relaçôes humanas com eles."

A compreensão do Ubuntu, de Desmond Tutu, Arcebispo da Igreja Anglicana da África do Sul, concorda com a dos autores acima mencionados. Ressalta Tutu (2004, p. 25):

Uma pessoa se torna pessoa através dos outros. Ninguém vem ao mundo já completamente formado. Não saberíamos pensar ou andar ou falar ou comportar como seres humanos se não o tivéssemos aprendido dos outros seres humanos. Precisamos de outros seres humanos para nos tornar humanos.

Percebemos, por esse axioma, que a ideia do Ubuntu inclui todo e qualquer ser humano como sendo valor absoluto. Ela enfatiza a importância dos outros na formação e no tornar-se humano do indivíduo. Isso mostra que, na constituição de relação, a identidade e a diferença coexistem, e os outros são constituintes do indivíduo, é a comunidade na qual se insere para se tornar humano. A comunidade e o indivíduo se constituem. A comunidade é o alicerce do pensamento e da vida dos africanos. Isso não quer dizer que o indivíduo se anule na comunidade ou renuncie a si, em prol da comunidade, mas que tudo o que fizer à comunidade, volta para si: se provocar o mal à comunidade, provoca-o a si mesmo; se buscar o bem para a comunidade, busca-o para si mesmo, beneficia-se a si mesmo. Aqui está a origem do pensamento africano, isto é, da filosofia africana.

Os acionamentos do Ubuntu, na África do Sul, justificariam um pensar no sistema democrático, baseado no modo de vida, caracterizado pelo diálogo, justiça restaurativa, comunitarismo, tolerância, reconciliação, perdão, inclusão, solidariedade e diversidade, seja com pares, seja com náo pares, diante de um sistema discriminatório, egoísta, antidemocrático e desumano de apartheid. A partir do aforismo atribuído ao Ubuntu, visto acima, entendemos que a existência do indivíduo só pode ser considerada humana, se ele reconhecer essa mesma humanidade nos outros, isto é, se ele tiver Ubuntu. A visão Ubuntu tem potencial de levar a uma política democrática, diferente daquela ocidental, imposta no país, após o período de apartheid.

Enquanto esse sistema democrático se pauta na vontade da maioria, o do Ubuntu se pautaria na tomada de decisáo consensual, levando em conta 
os interesses, possibilidades de "ser mais", direitos e deveres de todos, sem discriminação de raça, cor, gênero, orientação sexual etc. Com isso, cremos que a política africana, diferentemente da atual praticada no continente, orienta a uma forma de democracia muito diferente daquela ocidental. A democracia como modo de vida, com base no Ubuntu, intenciona

[...] providenciar uma ponte histórica entre o passado de uma sociedade profundamente dividida, caracterizada por conflitos, sofrimento incalculável e injustiça, e um futuro baseado no reconhecimento dos direitos humanos, da democracia e na coexistência pacífica e oportunidades de desenvolvimento para todos os sul-africanos, independentemente da cor, raça, classe, crença ou sexo. (TUTU, 2000, p. 39).

Logo, podemos deduzir algumas características estruturais inerentes ao Ubuntu, tais como comunidade/comunalismo e tolerância, conceitos que exploraremos nos tópicos a seguir.

\section{Comunidade}

O termo comunidade (do latim communitas), sociologicamente, pode ser aplicado a um grupo de pessoas que partilham dados em comum, como, por exemplo: localização geográfica, traços culturais (idioma, uso e costumes, história e valores) e visão cosmológica. Aqui, podemos aludir a comunidade familiar, comunidade religiosa, comunidade étnicas, tribais etc. Nelas, todo e qualquer membro tem noção de sua importância e participa ativamente em prol delas.

Bauman (2003, p. 08), referindo-se á importância da comunidade, na vida de um ser humano, relata:

[...] numa comunidade podemos contar com a boa vontade dos outros. Se tropeçarmos e cairmos, os outros nos ajudarão a ficar de pé outra vez. Ninguém vai rir de nós, nem ridicularizar nossa falta de jeito e alegrarse com nossa desgraça. Se dermos um mau passo, ainda podemos nos confessar, dar explicaçóes e pedir desculpas, arrepender-nos se necessário; as pessoas ouvirão com simpatia e nos perdoarão, de modo que ninguém fique ressentido para sempre. E sempre haverá alguém para nos dar a mão em momentos de tristeza. Quando passarmos por momentos difíceis e por necessidades sérias, as pessoas não pedirão fiança antes de decidirem se nos ajudarâo; não perguntarão como e quando retribuiremos, mas sim do que precisamos. E raramente dirão que não é seu dever ajudar-nos 
nem recusarão seu apoio só porque não há um contrato entre nós que as obrigue a fazê-lo, ou porque tenhamos deixado de ler as entrelinhas. Nosso dever, pura e simplesmente, é ajudar uns aos outros e, assim, temos pura e simplesmente o direito de esperar obter a ajuda de que precisamos.

A comunidade é um amparo ao ser humano. Na relação com os outros, o ser humano tem noção de pertença; sabe que são os outros que o equilibram novamente, toda vez que se desequilibra. Isso mostra que o indivíduo é interdependente com os pares, na comunidade. É essa a noção presente na filosofia africana e, consequentemente, no Ubuntu. Os conceitos usados na filosofia africana, para se referir à reflexão sobre a comunidade, são communalism (comunalismo) ou communitarianism (comunitarismo). Os dois derivam da palavra community (comunidade) e concernem à visão filosófica que concebe o ser humano enquanto ligado a seu contexto social e às suas tradiçôes culturais, e não a partir de seus traços egocêntricos.

Na dinâmica do Ubuntu, sustentada por Ramose, também está a comunidade africana, vista como uma associação dinâmica e contínua entre homens e mulheres, comprometendo-se uns com os outros e desenvolvendo-se num senso de pertença e de vida em comum, construída por seus membros, através da ação. Nessa perspectiva, pode-se sustentar que a história de vida individual, dentro dessa dinâmica de modo de vida em comum, se confunde com o compromisso de cada um com a comunidade e com sua visão moral do mundo. Em outras palavras, a história individual se prende à história comunitária. Comunitarismo africano representa o existencialismo cultural africano.

Uma visão interessante sobre comunitarismo, a qual nos dá uma clareza sobre a caracterização comunitária do Ubuntu, é a de Khoza (apud MOBOVULA, 2011, p. 39), para quem o comunitarismo concebe a humanidade "[...] em termos da existência coletiva e da intersubjetividade, servindo de base para o suporte, cooperação, colaboração e solidariedade.” Se perguntamos: por que suportar, cooperar, colaborar e ser solidário com o(s) outro(s)? - a resposta talvez seria, com/em Ubuntu, porque essas atitudes são boas em si mesmas e boas para o(s) outro(s) e para o indivíduo. A existência comunitária é formada pela existência de vários indivíduos, em uma relação dinâmica e contínua, na qual todos são sujeitos desse processo, por isso, vivem uma relação intersubjetiva. 
No Ubuntu, todos habitam e coabitam a comunidade. Não importaria se uns são brancos, negros, homens, mulheres, homossexuais, esquerdistas, direitistas, nordestinos, sulistas, cristãos, muçulmanos ou não. Com efeito, habitação e coabitação são "[...] propensão a viver com os outros de forma harmoniosa, não apenas em termos de espaço compartilhado, mas também [em termos de] acomodar as ideias de outras pessoas e de procurar compreender antes de tentar persuadir." (KHOZA apud MOBOVULA, 2011, p. 39). Essa visão existencial evidencia como os interesses do indivíduo sobre aspetos da vida e do bem comum estáo interlaçados com os interesses da comunidade. O senso comunitário faz parte da vida dos africanos, e é isso que caracteriza a africanidade dos africanos.

A problematização do comunitarismo africano não é uma questão acabada, resolvida, entre os pensadores africanos. O debate gira em torno da relação entre a comunidade e o indivíduo, defendida, de um lado, por comunitaristas "tradicionais", e, por outro, comunitaristas "modernos". Desse debate, que merece um estudo à parte, cabe destacar as ideias de Kwame Gyekye, o qual se considera moderno e suas ideias moderadas, com as quais concordamos, para sustentar nossa análise sobre Ubuntu.

Gyekye (2003) critica a visão de comunitarismo tradicional, classificado por ele de "radical" e "exagerado", proposta por "Jomo Kenyatta, John Mbiti e Ifeanyi Menkiti” (GYEKYE, 1997, p. 36-37), sustentando, particularmente, que a visão de Menkiti defende a primazia ontológica e a independência da comunidade sobre o indivíduo: "[...] na medida em que os africanos são considerados, a realidade do mundo comunal tem precedência sobre a realidade das histórias individuais de vida, quaisquer que estas sejam." (MENKITI, 1984, p. 171 apud GYEKYE, 2003, p. 350). Na interpretação de Ansah e Mensah (2018), a visão dos comunitaristas "radicais" parte do pressuposto de que o bem-estar, os valores e os objetivos da comunidade são supremos. Gyekye considera essa posição radical e excessiva, porque não permite o exercício dos direitos individuais: “[...] uma visão do comunitarismo que acho insuportável.” (GYEKYE, 2003, p. 351).

Gyekye, criticando a supervalorização do comunitário, define o seu próprio comunitarismo de "moderado", o qual adotamos nesta discussão sobre o Ubuntu. Escrevem Ansah e Mensah (2018, p. 66), comentando Gyekye: "A motivação para esta versão do comunitarismo [...] é para mostrar que os direitos individuais e por extensão a individualidade, são reconhecidos numa estrutura comunitária." Quando se fala dos aspetos comunitários, está-se a 
falar da caracterização das estruturas sociais que reflete o modo social de vida dos indivíduos. Entendemos que colocar ênfase no comunitário não significa ignorar ou anular o indivíduo, até porque é este que compóe a comunidade. É a luta ou o existir constante do indivíduo, na sua busca pelos direitos, que dá sentido à comunidade.

Na perspectiva do Ubuntu, pelo seu aforismo "uma pessoa se torna pessoa através de outras pessoas", revela que a qualidade do ser humano ou pessoa não é estática ou nata, mas adquirida e dinâmica. Pela análise desse axioma, isso não significa que são os outros que definem a humanidade/ pessoalidade do indivíduo. Não é suficiente ser interdependente dos outros, todavia, é necessária, sobretudo, a eticidade do indivíduo em reconhecer a humanidade presente nos outros. Assim, uma pessoa se torna pessoa, na medida em que ela reconheça a humanidade nas outras pessoas, isto é, na medida em que volta sua atitude para o bem da comunidade. Ressaltamos acima que o termo "comunidade" exige partilha dos interesses em comum. Por isso, Ubuntu nos leva a pensar na comunidade humana como modo de vida. O questionamento que levantamos a partir dessas ideias é o seguinte: é possível que a atitude do indivíduo seja contrária ao interesse humanitário comum? Em caso positivo, pode-se afirmar que esse indivíduo não é comunitário?

No pensamento africano, o indivíduo é intrinsecamente comunitário. Destaca Gyekye (2003, p. 351):

O comunitarismo imediatamente vê a pessoa humana como um ser inerentemente (intrinsecamente) comunitário, incorporado em um contexto de relaçóes sociais e interdependência, nunca como um indivíduo isolado, atômico. Por conseguinte, vê a comunidade não como uma mera associação de pessoas individuais cujos interesses e fins são contingentemente congruentes, mas como um grupo de pessoas ligadas por laços interpessoais, biológicos e /ou não-biológicos, que se consideram principalmente como membros do grupo e que têm interesses, objetivos e valores comuns. A noção de interesses e valores comuns é fundamental para uma concepção adequada da comunidade; essa noção de fato define a comunidade. É a noção de interesses, objetivos e valores comuns que diferencia uma comunidade de uma mera associação de pessoas individuais. Membros da comunidade compartilham objetivos e valores. Eles têm ligaçóes intelectuais e ideológicas, bem como emocionais, com esses objetivos e valores; enquanto estimá-los, eles estarão sempre prontos para persegui-los e defendê-los. 
Quando o interesse do indivíduo contradiz ou nega o interesse dos outros e da comunidade, caracterizando o individualismo, contradiz ou nega seu próprio interesse, porque, no individualismo, visto por Khoza (apud MOBOVULA, 2011, p. 39) como sendo filosofia política e social, colocase um "[...] alto valor na liberdade do indivíduo e enfatiza, de modo geral, um egocentrismo desenfreado." Diferentemente do pensamento africano, encontrado no Ubuntu, o indivíduo é interdependente da comunidade. E esta não deve ser um meio para a realização egoísta.

Gyekye (2003, p. 352) deduz as seguintes afirmações, a partir de sua concepção comunitária do ser humano:

1) Que a pessoa humana [ao nascer] não opta voluntariamente por entrar na comunidade humana, isto é, que a vida comunitária não é opcional para o indivíduo.

2) Que a pessoa humana é ao mesmo tempo um ser cultural.

3) Que a pessoa humana náo pode, talvez, não deva viver em isolamento de outras pessoas.

4) Que a pessoa humana é naturalmente tendenciosa a outras pessoas [isto é, manter relaçóes com elas].

5) Que as relaçóes sociais não são contingentes, mas necessárias.

A comunidade africana é a raiz e o berço por onde o indivíduo cresce e sobrevive. Por isso, pode-se assegurar que o neoliberalismo (nova forma de neocolonialismo), ao enfatizar o individualismo, gera não somente um impacto político, como também um impacto psicossocial, ético e ontológico na sociedade. Mbiti (1970, p. 286) se refere a isso, quando argumenta que "[...] a mudança moderna trouxe a muitas pessoas na África situaçóes totalmente desconhecidas na vida tradicional. A mudança significa que os indivíduos são cortados, apartados, retirados e separados da moralidade comunitária, costumes e solidariedade tradicional. Eles não têm mais raízes firmes."

É isso que acontece com os que foram tirados da África como escravos e, atualmente, também com muitos jovens africanos que desconhecem os valores, costumes, a moralidade tradicional de sua própria etnia. A maioria de jovens nas grandes cidades africanas é educada na lógica neoliberal. O próprio sistema educacional de muitos países africanos é baseado nos valores, na ética e nos costumes ocidentais. Esse foi o legado que o colonialismo e o neocolonialismo deixaram, isto é, tiraram as pessoas de sua cultura e ética, 
que as definem, sem substituí-las por outras. Mbiti (1970, p. 286) acrescenta: "Elas são simplesmente arrancadas, mas não necessariamente transplantadas. A solidariedade tradicional em que o indivíduo diz 'eu sou porque somos, e dado que somos, portanto eu sou', está constantemente sendo esmagada, minada e em alguns aspectos destruída." Chuwa (2014) acredita que, além da política e da economia, o neoliberalismo ainda impóe, na África, uma cultura alheia ocidental, isto é, substituiu o "Nós" da comunidade tradicional pelo "Eu" do individualismo moderno.

O caráter comunitário do Ubuntu nos mostra que o ser humano é relacional e interdependente, devido à sua sociabilidade natural. Por sociabilidade natural, concebemos as relaçóes necessárias entre o indivíduo e a comunidade, as quais complementam um ao outro. Isso quer dizer que, sem essas relações, o indivíduo não se torna aquilo que é, em termos de ser humano. É nessa complementaridade com a comunidade que o indivíduo realiza suas possibilidades, expressando sua individualidade na formação de sua pessoalidade. É importante realçar que, na comunidade, não se coloca ênfase na posse individual, isto é, no ter do indivíduo, mas em seu ser em relação, em comunhão ${ }^{8}$ com os outros. Concordamos com a ideia de que, no comunitarismo, o indivíduo só se torna ser humano na interconexão com os outros, reconhecendo a humanidade desses. Isso significa que são as outras pessoas que nos despertam para a busca dessa humanidade. Por isso, a afirmação de que a realização do ser humano do indivíduo depende dos outros.

Logo, a partir da discussão de Gyekye, defendemos que há, na comunidade, tanto direitos quanto deveres do indivíduo que se complementam com os dos outros. Defender a primazia da comunidade é anular os direitos individuais, isto é, o indivíduo se torna totalmente objeto do grupo. Com essa anulação, não podemos afirmar que haja uma relação intersubjetiva e interdependente. No nosso entender, o dever com o grupo é o dever com o(s) outro(s), é compromisso com seus direitos, com os valores democráticos.

${ }^{8}$ A comunhão aqui reflete a vida comunitária. Assinala Franken (apud MAKUMBA, 2014, p. 184): "O povo africano tinha uma filosofia de vida [...] As pessoas viviam em pequenas comunidades... Elas precisavam umas das outras. As mulheres não podiam ir sozinhas apanhar lenha ou buscar água à floresta, ou capim para os telhados. E nem o caçador podia ir sozinho buscar comida para a sua família. Eles tinham de juntar forças e trabalhar juntos. A partir desta necessidade natural, foi-se formando uma certa filosofia de vida [...] todos aceitavam o dever de trabalhar, e os direitos eram concedidos segundo os frutos do trabalho comunitário." 
Na visão de Nyamwe e Mkabela, citados por Castiano (2010, p. 169), esses direitos e deveres democráticos

[...] não estão em contradição com os valores e as práticas tradicionais nas comunidades africanas. Pelo contrário, o indaba ou hurukuro (o exercício da palavra nas comunidades africanas) promovia capacidade de busca de consensos para decisóes coletivas, embora o teor do consenso aqui não seja necessariamente baseado no ponto de vista da maioria, como é a norma das democracias ocidentais.

O egocentrismo, o qual apenas se serve dos outros como meio para ter mais, a alienação, a exploração e a desumanização dos outros são desestimulados. No pensamento africano, o modo ganancioso desumaniza o indivíduo, justamente por ele desumanizar os pares. O foco é privilegiar sua humanização, que se dá na sua interconexão, na tolerância para com os outros, que será nosso próximo item a ser discutido.

\section{TOLERÂNCIA}

Por ser qualidade humana, isto é, valor que se deve alcançar, o Ubuntu exige tolerância entre as pessoas, pelo fato de elas comporem a comunidade, possuírem e compartilharem os dados socioculturais em comum. O conceito de tolerância pode ser interpretado em função de vários sentidos, como teológico, político e social. No Dicionário de Filosofia de Mora (2004), o autor nos traz esses três sentidos da tolerância. Ele chamou de "tolerância", no sentido teológico, as indulgências dadas a certas doutrinas ou determinadas obras, isto é, absolvição dessas doutrinas ou obras, por motivo de misericórdia. Ou seja, há tolerância para com essas doutrinas, pelo fato de terem sido absolvidas de uma rejeição ou condenação. A tolerância no sentido político diz respeito à aceitação de doutrinas ou ideias, práticas políticas, "[...] desde que se achem dentro da ordem prescrita e aceita livremente pela comunidade." (MORA, 2004, p. 2879). E, por fim, o sentido social concerne à compreensão de ideias contrárias entre as pessoas, a ponto de facilitar a convivência. Interessa-nos esses dois últimos sentidos, pois é exatamente o que o Ubuntu propóe.

Quando aludimos a tolerância do ponto de vista socioético, admitimos que há diversas formas de pensar, diversas ideias e diversas formas de agir das pessoas. Isto é, só tratamos de tolerância, porque há convivência em termos sociais. Em termos do Ubuntu, a tolerância é inata, isto é, um 
valor que os seres humanos possuem, "[...] pela profunda compreensão das pessoas sobre as origens, evolução e conquistas da humanidade de um lado, e pela exploração daquilo que é comum e diversos no patrimônio cultural, do outro." (MABOVULA, 2011, p. 41). Essa ideia é ainda mais imprescindível, em um país que abarca várias tribos, línguas, religiōes e raças diferentes. Isso não significa que não possa haver discordâncias entre as pessoas. É normal discordar, o que revela que não há apenas uma perspectiva pela qual se vê uma ideia, um problema etc. A discordância é saudável e enriquecedora aos seres humanos. No entanto, ela não pode ser usada para causar sofrimento, danos às pessoas.

No pensamento africano, tolerar é respeitar o ponto de vista dos outros, como coexistência que compóe a estrutura comunitária. Se os outros são seres diferentes, com os quais existimos, essa coexistência deve exigir tolerância dos dois, porque, sem tolerância, não podemos pensar em liberdade, colaboração, que são valores necessários aos indivíduos, em seu desenvolvimento e conquistas dentro da comunidade. A comunidade precisa ser tolerante para com o indivíduo e vice-versa. Por isso, entendemos que qualquer juízo moral da comunidade deve partir de uma discussão e debate dos membros que compóem essa comunidade. Ou seja, deve envolver a participação de todos na elaboração do juízo moral.

A tolerância, do ponto de vista político, demanda respeito e compreensão das diferentes teorias, opinióes, culturas coexistentes na sociedade. Aqui, tomamos essa dimensão política por uma sociedade mais ampla em nível do Estado, composta por várias e diferentes comunidades. Falar de tolerância do Estado é falar de seu reconhecimento de todas as comunidades que o compóem. O Estado, para ser democrático, deve tolerar suas comunidades, isto é, deve haver tolerância entre as comunidades.

A história nos mostrou as consequências da intolerância por parte do Estado, em várias partes do mundo. Foi o que aconteceu com os sul-africanos, antes e durante a aplicaçáo da política de apartheid pelo Estado, onde os negros não foram reconhecidos em suas diferenças. Pelo contrário, foram forçados e dominados em todos os sentidos, oprimidos, explorados, marginalizados. Suas particularidades, em termos de patrimônio cultural e epistemológico, foram ignoradas e consideradas "primitivas" (selvagens); foram obrigados a aderir à religiáo, à língua, aos valores epistemológicos e aos comportamentos dos brancos, impostos como sendo "o verdadeiro patrimônio cultural". A 
intolerância entre as comunidades causou guerra civil, em várias partes do mundo.

É perigoso o Estado assumir uma determinada posição cultural ou religiosa de uma das tribos (comunidades) que o constituem, pois isso significa não reconhecer as outras culturas. E, pior, as outras podem se sentir obrigadas a aderir à posição do Estado, a qual, ao nosso ver, seria culpabilizar a vítima. Será que o Brasil atual não está rumando para esse caminho perigoso, com as posiçóes políticas e culturais de seus governantes, defendidas no âmbito público? Assistimos a um tremendo esforço de vários membros do governo em abordar uma única "cultura brasileira", criar leis de "bons costumes". É curioso, porque a suposta "cultura brasileira" e os supostos "bons costumes", defendidos por conservadores de extrema direita, se referem à cultura judaico-cristâ. A comunidade judaico-cristã é a única que habita e compóe o Brasil? Se o Estado defende essa pauta, não está assim ignorando a cultura e a religião de outros seus cidadãos, descendentes de África, de Ásia, islâmicos e as culturas nativas?

Uma das grandes ameaças atuais da intolerância é a polarização feita pelos movimentos extremistas. Esses movimentos acreditam que são donos da verdade e são "salvadores" do mundo. Qualquer um que discorde deles é visto como inimigo, o qual deve ser eliminado, porque representa perigo para eles. Assim, os outros são tidos como ameaças. Eles têm dificuldade em reconhecer a multiculturalidade de suas sociedades. Esse não reconhecimento, na opinião de Taylor (1994), causa sérios danos às pessoas, comunidades e sociedade como um todo. Assinala Taylor (1994, p. 25):

A demanda por reconhecimento [nas políticas de reconhecimento] é dada urgência pelos supostos vínculos entre reconhecimento e identidade, onde a identidade refere-se a compreensão de uma pessoa de quem ela é, de suas características fundamentais como um ser humano. A tese é que nossa identidade é parcialmente moldada pelo reconhecimento ou não-reconhecimento, muitas vezes pelo mau reconhecimento dos outros, e assim uma pessoa ou grupo de pessoas pode sofrer danos reais, distorção real, se as pessoas ou a sociedade ao seu redor produzir uma imagem estereotipada sobre ele. Não reconhecimento ou mau reconhecimento pode infligir danos, pode ser uma forma de opressão, aprisionando alguém em um modo de ser falso, distorcido e reduzido.

A democracia estabelece tolerância política, social e religiosa, que é o reconhecimento de todos, nas suas diversidades. É uma política que abarca 
todos, na qual os outros se sentem parte do todo, mesmo sendo diferentes. Políticas contrárias seriam políticas desumanas. O Brasil é uma sociedade multicultural, miscigenada, isto é, composta por várias culturas (BRASIL, 2010). Por isso, a política pública não pode ser compreendida em valores culturais específicos. Ou seja, o Estado não deveria privilegiar uma cultura, em detrimento de outras, isto é, sobrepô-la. O que se exige é tolerância entre todas as culturas. A tolerância, conforme Rawls (1999), não é apenas omitir, mas também é promover as ideias, valores, culturas, religióes contrárias aos seus. A discriminação cultural gera déficit de reconhecimento moral, que pode gerar consequências graves na vida das pessoas e da sociedade.

Obviamente, em nossa discussão, as duas dimensôes de tolerância (socioética e política) estão conectadas, porque é a dimensão socioética que gera a dimensão política e esta influencia a primeira. No Ubuntu, a tolerância acontece primeiro na dimensão ético- moral, dentro da comunidade, em função do reconhecimento do indivíduo aos outros e vice-versa, como seres interdependentes, e, depois, ela acontece ipso facto na dimensão política.

Como pensar em uma política democrática, quando à maioria são roubados os seus direitos? Quando há um sistema de competitividade, no qual a maioria é usada para produzir e acumular riquezas para minoria? Não é esse o pensamento da política ideológica do individualismo, propagada pelo capitalismo, através da globalização, camuflada de neoliberalismo? Nesse pensamento, o foco está no ter mais do indivíduo, em detrimento do ter menos dos outros e náo no ser em si. No neoliberalismo, tudo se converte em forma de dinheiro, isto é, os outros são pensados a partir da lógica empresarial. Por essa incoerência, Freire (2002) considera essa política antidemocrática ou inexperiência democrática, justamente por esse descompasso entre a ideologia (teoria) e a prática (a vivência). A noçấo da democracia deve implicar a coerência entre as disposições internas, em termos epistemológicos, com "quefazer" (expressão usada por Freire) externos, isto é, entre a teoria e a prática. Segundo Freire (2015, p. 64),

[...] a democracia, como qualquer sonho, não se faz com palavras desencarnadas, mas com reflexão e prática. Não é o que digo o que diz que eu sou democrata, que não sou racista ou machista, mas o que faço. É preciso que o que eu diga não seja contraditado pelo que faço. É o que faço que diz de minha lealdade ou náo ao que digo. 
Igualmente, dessa concepção, o pensamento africano Ubuntu traz duas perspectivas, em termos de ser e do existir entre o indivíduo e o coletivo: complementaridade e procedimento (ético). Na perspectiva de complementaridade, acredita-se que o indivíduo é um ser incompleto, inconcluso, inacabado, razão pela qual se coloca em busca constante de sua melhoria com o(s) outro(s). Segundo Freire (2006), é por consciência do inacabamento que o ser humano transcende a si mesmo ao encontro do(s) outro(s). Isso quer dizer que o "eu" é parte dos outros, e vice-versa. Ewulu (apudKANU, 2017, p. 103) descreve melhor essa perspectiva, sem diminuição e sem inferioridade, quando assevera:

\begin{abstract}
Se o outro é a minha parte ou um pedaço de mim, significa que eu preciso dele para estar completo, para ser o que realmente sou. $\mathrm{O}$ outro me completa ao invés de me diminuir. Sua linguagem e cultura destacam e, ao mesmo tempo, enriquecem e complementam as minhas [...] uma vez colocadas juntas as minhas e as do outro, formam um todo mais rico, do que quando estão separadas.
\end{abstract}

Em termos éticos, o indivíduo é um ser comunitário. Em consequência, consegue sua autopercepção na e pela comunidade. De novo, Ewulu (apud KANU, 2017, p. 103) o enfatiza, da seguinte maneira: "Eu me percebo no outro porque é no 'Tu-dade' do Tu que meu 'ser-dade' é realizado. Eu sou 'eu' porque você é 'Você'. Sem você não há eu. Somos 'Nós' porque eles são 'Eles', e sem 'Eles', não há 'Nós'.” São os outros que chamam o indivíduo à existência. Ou seja, a identidade é absorvida na alteridade, porque o indivíduo é parte da comunidade que é diferente. E só me torno eu quando deixo os outros serem.

\title{
ConsideraÇóes Finais
}

$\mathrm{Na}$ visão do mundo africano, as duas realidades (metafísica e fenomenológica) interagem e se relacionam, constantemente. Isto é, há uma relação de interdependência entre elas. Essas inter-relações e interaçôes de interdependência constantes entre os pares humanos e com os seres espirituais criam um modo particular de viver a vida, a partir de uma visão comunitária, que talvez possamos chamar de experiência democrática ou africanizaçáo da democracia. Essa ideia não se assemelha à noçáo de democracia de Dewey (1958), a qual é uma experiência de vida conflitiva, que acontece em todas as 
esferas da vida na natureza? Abrimos, assim, a possibilidade de ampliar essa análise em outros estudos.

Nessa democracia comunitarista africana, a identidade (o eu africano) só pode existir com os outros, isto é, só pode ser com, implicando uma existência comunitária. Náo existiria o eu sem os outros e vice-versa, reforçando a citação de Mbiti (1970, p. 141), vista acima: "Eu sou porque Nós somos; e dado que somos, por isso Eu sou." A humanização do Eu depende da humanização dos outros. O que acontece com um é sentido ou experienciado por todos. Esse pensamento pode ser representado por uma teia de barbante construída por um grupo de pessoas, quando cada pessoa segura na ponta do dedo uma parte dessa teia. Se uma pessoa decidir puxar fortemente sua parte, as outras ficarão com seus dedos machucados. Frisa Tempels (1959, p. 41): "O mundo das forças é como uma teia de aranha da qual nenhum fio pode vibrar sem abalar toda a rede."

Sendo a expressão da visão de vida africana, isto é, a forma como os africanos enxergam o mundo, a marca de consciência coletiva (comunidade) do Ubuntu se manifesta nas ações, isto é, no comportamento, nas expressóes linguísticas e no aspecto espiritual, concretizando assim certos valores, tais como fraternidade, partilha e trato das pessoas como seres humanos que são. Assim, Ubuntu pode ser considerado o senso da identidade dos africanos e por que não? - sua conquista. É conquista exatamente por ajudar os africanos a problematizarem e lidarem com seus problemas diários, de forma positiva, através de sua herança tradicional de valores humanísticos e epistêmicos, passada de geração em geração.

Com esse senso de identidade, podemos assegurar que a África pode cooperar no pensamento da democracia, com a aplicação desses valores, no modo de vida, para resolver os problemas da humanidade ou problematizálos. Essa ideia de contribuição é secundada por Makumba (2014, p. 231, nos seguintes termos: "A África tem um papel a desempenhar nos assuntos internacionais contemporâneos e na política global. A Filosofia deve esforçar-se por colocar o africano em sintonia com a sua vocação, que, em última análise, não é apenas a vocação do africano, mas a de todo o género humano $[\ldots] "$

Cada ser humano, sendo membro da comunidade humana, usufrui de status de igualdade com os outros, na diferença funcional da comunidade. Essa igualdade consiste na deliberação dos membros diante dos propósitos e 
objetivos da comunidade. Isso pressupóe a participação, liberdade, diálogo, tolerância, que são precondiçóes para as práticas de justiça restaurativa e distributiva, nas quais a comunidade política deve se envolver.

No Ubuntu como modo de vida, não há como a comunidade política desrespeitar os direitos básicos dos indivíduos, pois sua ética normativa tende à humanização de todos. Todavia, o indivíduo, pela liberdade, pode optar por não ter Ubuntu, se fizer uso dos outros meios para sua realização egoísta, isto é, se desumanizar os outros para poder ser. Numa democracia, os interesses individuais não se anulam. As subjetividades individuais não são superiores e nem inferiores, mas são consideradas em relação com as dos outros (intersubjetividade), perante a fidelidade à causa comum. Ubuntu possibilita aos seres humanos viverem democraticamente, dialogando-se de forma honesta e tolerante. Com o Ubuntu, as diferentes ideologias, culturas e visão do mundo se interconectam e enxergam o ser humano como fim em si mesmo. É isso que Tutu afirma, na sua conceituação do Ubuntu: "[...] uma pessoa se torna pessoa através de outras pessoas. Desumanizar uma pessoa inexoravelmente significa desumanizar a si mesmo" (TUTU, 2000, p. 31).

O pensar a democracia passa pela educação, a qual deve ter como background a coletividade. O modo de vida e a educaçáo estão interconectados. Ubuntu é essencial para pensar a educação democrática. Defendemos que Ubuntu deva fazer parte da política educacional, da coerência entre a teoria e prática dos sujeitos da educaçáo. Isso significa ter Ubuntu embutido na coletividade do processo, no agir pedagógico interdependente, na participação da problematização deliberativa e na ação social responsável. Todos, sendo sujeitos educacionais, participam da educação como experiência humana, na qual se suporta uma ética democrática pela coerência entre a criticidade do ensino-aprendizagem e a vivência, que leva à tolerância, liberdade, empatia, ao reconhecimento dos outros e à humanização de todos. De fato, a educação deve mirar o bem comum da comunidade.

DJU, A. O.; MURARO, D. N. Ubuntu as a way of life: the contribution of african philosophy to think about democracy. Trans/Form/Açáo, Marília, v. 45, p. 239-264, 2022. Edição Especial. 


\begin{abstract}
This study aims at analysing the notion of Ubuntu as a contribution to think about democracy, especially the crisis it faces in Brazil, before the current historical reality of intolerance, racial discrimination, social exclusion, and dehumanization. For this reason, we raise the following question: can Africa contribute to think about democracy through her life's philosophy expressed in Ubuntu? The first part of the text analyses the concept of Ubuntu, highlighting its philosophical character. The second part develops two structural characteristics of Ubuntu: community and tolerance. The research methodology is characterised as a bibliographical work, whose contribution is a philosophical analysis of the expression Ubuntu, based on the African way of life, from the works of Ramose: African Philosophy Through Ubuntu (2005); of Gyekye: Person and community in African thought (2003). We defend that understanding Ubuntu as an African way of life, based on interdependence, inter-constitution, interconnection and inter-humanisation is to contribute to think about democracy as an ethical, social and political way of life that recognises and considers the other(s) as individual(s) of differences that make humanisation possible.
\end{abstract}

Keywords: Ubuntu. Community. Tolerance. Democracy. African Philosophy.

\title{
REFERÊNCIAS
}

ANSAH, Richard; MENSAH, Modestha. Gyekye's Moderate Communitarianism: A Case of Radical Communitarianism in Disguise. 2018. Disponível em: https://www. researchgate.net/publication/328796791_Gyekye's_moderate_communitarianism_a_ case_of_radical_communitarianism_in_disguise. Acesso em: 22 dez. 2020.

BAUMAN, Zygmunt. Comunidade: a busca por segurança no mundo atual. Trad. De Plínio Dentzien. Rio de Janeiro: Jorge Zahar, 2003.

BRASIL. Diretrizes Curriculares da Educação Básica. 2010. Disponível em: http:// portal.mec.gov.br/index.php?option=com_docman\&view=download\&alias=1554 8-d-cn-educacao-basica-nova-pdf\&Itemid=30192. Acesso em: 05 mar. 2018.

CASTIANO, José P. Referenciais da Filosofia Africana: em busca da intersubjectivação. Maputo: Ndjira, 2010.

CHUWA, Leonard Tumaini. African Indigenous Ethics in Global Bioethics: Interpreting Ubuntu. V. 1. New York: Springer, 2014.

DEWEY, John. Experience and Nature. London: George Allen \& Unwin, 1929.

DJU, Antonio Oliveira. Alteridade e Educaçáo: uma contribuição de Paulo Freire e da filosofia Ubuntu para uma educação humanizadora. 2021.152 f. Dissertação (Mestrado em Educação). Universidade Estadual de Londrina, Londrina, 2021.

FREIRE, Paulo. Pedagogia do Oprimido. 22. ed. Rio de Janeiro: Paz e Terra, 1987.

FREIRE, Paulo. Educaçáo e Atualidade Brasileira. 2. ed. Sáo Paulo: Cortez; Instituto Paulo Freire, 2002.

FREIRE, Paulo. Educação como Prática da Liberdade. 29. Ed. Rio de Janeiro: Paz e Terra, 2006. 
FREIRE, Paulo. Pedagogia da Autonomia: saberes necessários à prática educativa. São Paulo: Paz e Terra, 2011.

FREIRE, Paulo. Professora, Sim; Tia, Náo: cartas a quem ousa ensinar. 24. ed. Rio de Janeiro: Paz e Terra, 2015.

GADE, Christian B. N. The Historical Development of the Written Discourses on Ubuntu. South African Journal of Philosophy, v. 30, n. 3, 2011. Disponível em: http://pure.au.dk/portal/files/40165256/The_Historical_Development_of_the_Written_ Discourses_on_Ubuntu.pdf. Acesso em: 10 dez. 2019.

GYEKYE, Kwame. Person and community in African thought. In: COETZEE, P. H.; ROUX, A. P. J. (ed.). The African Philosophy Reader. 2. ed. New York: Routledge, 2003. p. 348-366.

KANU, I. A. African Philosophy: a hermeneutic aproach to African Traditional Religion, Theology and Philosophy. Jos: Augustinian, 2015.

KANU, I. A. African Philosophy, Globalization and the Priority of 'Otherness'. In: IGWEBUIKE: An African Journal of Arts and Humanities, v. 3 n. 5, 2017. Disponível em: http://igwebuikejournals.com/pdf\%20created/3.5.7.pdf. Acesso em: 10 ago. 2018.

MABOVULA, Nonceba Nolundi. The Erosion of African Communal Values: a reapraisal of the African ubuntu philosophy. Inkanyiso: Journal of Humanities and Social Sciences, v. 3, n. 1, 2011. Disponível em: https://www.ajol.info/index.php/ijhss/article/ viewFile/69506/57525. Acesso em: 20 abril 2019.

MAURICE, M. Makumba. Introdução à Filosofia Africana: Passado e Presente. Trad. De Mário de Almeida. São Paulo: Paulinas; Prior Velho, 2014.

MBITI, John. African Religious and Philosophy. New York: Anchor Books, 1970.

MORA, Jose Ferrater. Dicionário de Filosofia. Tomo IV. 2. ed. São Paulo: Loyola, 2004.

NABUDERE, Dani W. Ubuntu Philosophy: Memory and Reconciliation. Texas Scholar Works, 2005. Disponível em: https://repositories.lib.utexas.edu/handle/2152/4521.

Acesso em: 10 fev. 2020.

RAMOSE, Mogobe B. African Philosophy Through Ubuntu. Harare: Mond Books, 2005.

RAWLS, John. The Law of People: with The Idea of Public Reason Revisited. Cambridge; Massachusetts; London: Harvard University Press, 1999.

TAYLOR, Charles. The Politics of Recognition. In: GUTMANN, Amy (org.).

Multiculturalism: Examining the Politics of Recognition. New Jersey: Princeton, 1994. p. $25-73$

TEMPELS, Placid. Bantu Philosophy. Paris: Présence Africaine, 1959.

TUTU, Desmond. No Future Without Forgiveness. New York: Doubleday, 2000. 
DJU, A. O.; MURARO, D. N.

TUTU, Desmond. God Has a Dream: a Vision of Hope for our Time. New York: Doubleday, 2004.

Recebido: 22/7/2020

Aceito: 06/01/2021 